\title{
Retrograde Viral Vector-Mediated Inhibition of Pontospinal Noradrenergic Neurons Causes Hyperalgesia in Rats
}

\author{
Patrick W. Howorth, ${ }^{1}$ Simon R. Thornton, ${ }^{1}$ Victoria 0’Brien, ${ }^{1}$ Wynne D. Smith, ${ }^{1}$ Natalia Nikiforova, ${ }^{2}$ \\ Anja G. Teschemacher, ${ }^{1}$ and Anthony E. Pickering ${ }^{1,3}$ \\ ${ }^{1}$ Department of Physiology \& Pharmacology, University of Bristol, Bristol BS8 1TD, United Kingdom, ${ }^{2}$ Department of Physiology, Anatomy and Genetics, \\ University of Oxford, Oxford OX1 3QX, United Kingdom, and ${ }^{3}$ Department of Anaesthesia, University Hospitals Bristol, Bristol BS2 8HW, United Kingdom
}

\begin{abstract}
Pontospinal noradrenergic neurons form a component of an endogenous analgesic system and represent a potential therapeutic target. We tested the principle that genetic manipulation of their excitability can alter nociception using an adenoviral vector (AVV-PRS-hKir ${ }_{2.1}$ ) containing a catecholaminergic-selective promoter (PRS) to retrogradely transduce and inhibit the noradrenergic neurons projecting to the lumbar dorsal horn through the expression of a potassium channel $\left(\mathrm{hKir}_{2.1}\right)$. Expression of $\mathrm{hKir}_{2.1}$ in catecholaminergic PC12 cells hyperpolarized the membrane potential and produced a barium-sensitive inward rectification. LC neurons transduced by AVV-PRShKir $_{2.1}$ in slice cultures also showed barium-sensitive inward rectification and reduced spontaneous firing rate (median $0.2 \mathrm{~Hz} ; n=19 \mathrm{vs}$ control $1.0 \mathrm{~Hz} ; n=18, p<0.05$ ). Pontospinal noradrenergic neurons were retrogradely transduced in vivo by injection of AVV into the lumbar dorsal horn (L4-5). Rats transduced with AVV-PRS-hKir ${ }_{2.1}$ showed thermal but not mechanical hyperalgesia. Similar selective augmentation of thermal hyperalgesia was seen in the CFA-inflammatory pain model after AVV-PRS-hKir ${ }_{2.1}$. In the formalin test, rats transduced with $\mathrm{hKir}_{2.1}$ showed enhanced nocifensive behaviors (both Phase I and II, $p<0.05, n=11$ /group) and increased c-Fos-positive cells in the lumbar dorsal horn. Transduction with AVV-PRS-hKir ${ }_{2.1}$ before spared nerve injury produced no change in tactile or cold allodynia. Thus, the selective genetic inhibition of $\sim 150$ pontospinal noradrenergic neurons produces a modality-specific thermal hyperalgesia, increased nocifensive behaviors, and spinal c-Fos expression in the formalin test, but not in the spared nerve injury model of neuropathic pain, indicating that these neurons exert a selective tonic restraining influence on in vivo nociception.
\end{abstract}

\section{Introduction}

The degree of pain perceived in response to a given noxious stimulus is greatly influenced by the context within which the injury is suffered (Melzack et al., 1982). In part, this variation is attributable to the engagement of endogenous analgesic mechanisms within the CNS that act to modulate pain. Since the report that electrical stimulation of the mid-brain produces profound analgesia (Reynolds, 1969), much attention has focused on descending control systems which can influence the spinal transmission of noxious inputs (Millan, 2002; Fields, 2004). The norepinephrine (NE)-containing neurons of the locus ceruleus (LC), A5 and A7 cell groups in the pons have been implicated as key components of this descending control system (Jones, 1991; Millan, 1997; Pertovaara, 2006).

These neurons send axonal projections to the spinal dorsal horn which release NE (Crawley et al., 1979; Hentall et al., 2003) that acts via $\alpha 2$-adrenoceptors to inhibit both primary afferents and second order projection neurons (Reddy et al., 1980; Hammond and Yaksh, 1984; North and Yoshimura, 1984; Jones

\footnotetext{
Received April 8, 2009; revised June 28, 2009; accepted July 6, 2009.

A.E.P. is a Wellcome Advanced Clinical Fellow. A.G.T. is a British Heart Foundation Research Fellow. We thank

Sergey Kasparov and Julian Paton for their advice, support, and generous contributions to this work.

This article is freely available online through the J Neurosci Open Choice option.

Correspondence should be addressed to Anthony E. Pickering, Department of Physiology and Pharmacology,

School of Medical Sciences, University of Bristol, Bristol BS8 1TD, UK. E-mail: Tony.Pickering@Bristol.ac.uk.

DOI:10.1523/JNEUROSCI.1699-09.2009

Copyright $\odot 2009$ Society for Neuroscience ～0270-6474/09/2912855-10\$15.00/0
}

and Gebhart, 1986a; Miller and Proudfit, 1990; Sonohata et al., 2004). Stimulation of the pontine noradrenergic (NAergic) cell groups has been shown to be analgesic in a number of acute pain models (Jones and Gebhart, 1986a,b; Miller and Proudfit, 1990; Jones, 1991; Yeomans et al., 1992; West et al., 1993) and they are activated in stressful situations [e.g., swim stress analgesia (Bodnar et al., 1985)]. In chronic neuropathic pain models there are plastic changes in the NAergic innervation of the spinal dorsal horn and alterations in $\alpha 2$-adrenoceptor sensitivity (Ma and Eisenach, 2003; Hayashida et al., 2008). This endogenous pain modulating system is also important in clinical practice as several analgesic drugs are believed to act by mimicking or modulating these NAergic neurons and are used in the treatment of acute (e.g., tramadol, clonidine) and chronic pain [tricyclic antidepressants, duloxetine or intrathecal clonidine (Eisenach et al., 1995)].

Therefore the pontospinal NAergic neurons represent a potential target for therapeutic genetic intervention. We have previously demonstrated these neurons can be retrogradely transduced using an adenoviral vector (AVV) with a catecholaminergic-selective promoter (Howorth et al., 2009). In the current study we have tested the principle that genetic manipulation of these noradrenergic neurons can alter nociception. We hypothesized that inhibiting the activity of these NAergic neurons, through the selective expression of a "leak" potassium channel $\left(\mathrm{hKir}_{2.1}\right)$, will enhance the responsiveness to acute and chronic noxious stimuli in vivo. 


\section{Materials and Methods}

Experiments were performed on male Wistar rats $(n=116$, University of Bristol colony). All procedures conformed to the UK Animals (Scientific Procedures) Act 1986 and were approved by our institutional ethical review committee. Animals were group housed, with an enriched environment, on thick sawdust bedding and under a standard $12 \mathrm{~h}$ light/dark cycle, with ad libitum access to food and water.

\section{Adenoviral vector constructs and preparation}

The control vector AVV-PRS-EGFP employs a 240-bp catecholaminergicselective promoter PRSx8 promoter sequence (Hwang et al., 2001) that restricts the expression of the transgene-enhanced green fluorescent protein (EGFP) - to a subset of neurons that express the Phox2 transcription factor. We have previously described its preparation (Lonergan et al., 2005) and use to express fluorophores for detailed anatomical studies of pontospinal NAergic neurons (Howorth et al., 2009).

AVV-PRS-hKir ${ }_{2.1}$ was created from a previously described lentiviral vector expression cassette which was transferred into an adenoviral backbone AVV-PRS-hKir ${ }_{2.1}$ (Duale et al., 2007). The PRSx8 promoter was used to drive expression of both $\mathrm{hKir}_{2.1}$ a human inwardly rectifying potassium channel gene (Kubo et al., 1993) (plasmid kindly donated by Dr David C. Johns, Johns Hopkins University School of Medicine, Baltimore) and EGFP through the use of an internal ribosomal entry site. To take advantage of the bidirectional activity of the PRSx8 promoter (Duale et al., 2007) (see also Amendola et al., 2005), an additional copy of EGFP was placed in antisense orientation upstream of the PRSx8 promoter to enhance the level of EGFP fluorescence.

AVVs were obtained by homologous recombination of shuttle with helper plasmids and proliferation in $\mathrm{HEK} 293$ cells, followed by $\mathrm{CsCl}$ gradient purification, using standard techniques (Graham and Prevec, 1995). The AVV stocks were titerd by an immuno-reactivity "spot" assay (goat anti-hexon antiserum, Biodesign International) according to previously published protocols (Bewig and Schmidt, 2000; Duale et al., 2005) and titers were determined as transducing units (TU) per ml.

\section{Cell culture}

Catecholaminergic PC12 cells were seeded on glass covers slips coated with Matrigel (BD Biosciences, Bedford, MA, USA) in serum-supplemented Dulbecco's Modified Eagle Medium. The cells were transfected with shuttle plasmid DNA for either AVV-PRS-hKir ${ }_{2.1}$ or AVV-PRS-EGFP $(2.5 \mu \mathrm{g} /$ well) using SuperFect (Qiagen). After transduction, cells were differentiated with nerve growth factor $\left(\mathrm{NGF}, 50 \mathrm{ng} \cdot \mathrm{ml}^{-1}\right)$. Both plasmids produced visible EGFP fluorescence in PC12 cells (typically in $\sim 10 \%$ of PC12 cells). However, the fluorescence induced by the AVVPRS-hKir ${ }_{2.1}$ plasmid was dimmer, as expected, given the decreased level of expression of gene products placed downstream of an IRES or upstream of a promoter in antisense orientation.

\section{Slice culture}

Brainstem slice cultures were prepared as described previously (Stoppini et al., 1991; Teschemacher et al., 2005; Wang et al., 2006). Briefly, Wistar rat pups [postnatal days $7-8(\mathrm{P} 7-8), n=45$ ] were terminally anesthetized with halothane. The brainstem was removed and bathed in ice-cold dissection medium. Slices of the pons were cut $(250 \mu \mathrm{m}$ thick, coronal or longitudinal) in cold $\left(4^{\circ} \mathrm{C}\right)$ sterile dissection solution using a Vibratome (Vibroslice, Campden Instruments) and kept on ice for $1 \mathrm{~h}$. Two or three slices were plated on each organotypic culture insert (MillicellCM, Millipore) in Optimem-1-based medium (Stoppini et al., 1991; Teschemacher et al., 2005; Wang et al., 2006) containing AVV (either AVV-PRS-EGFP alone or a 2:1 mixture of AVV-PRS-hKir ${ }_{2.1}$ :AVV-PRSEGFP). Slices were incubated at $37^{\circ} \mathrm{C}$ in a $5 \% \mathrm{CO}_{2}$ atmosphere. After $3 \mathrm{~d}$, the plating medium was exchanged for supplemented Neurobasal medium, which was subsequently changed twice a week (Stoppini et al., 1991; Teschemacher et al., 2005; Wang et al., 2006). Slice cultures were allowed to settle for $7 \mathrm{~d}$ before being used for experimentation. After electrophysiological recordings some of the organotypic slice cultures were fixed in $5 \%$ formalin for $20 \mathrm{~min}$ and then washed $(\times 3)$ in $0.1 \mathrm{M}$ phosphate buffered $0.9 \% \mathrm{NaCl}$ ( $\mathrm{pH}$ 7.4, PBS). The tissue sections were teased from the supporting membrane, mounted on slides and processed for immunohistochemistry (IHC; see below).

\section{Electrophysiology}

After transduction, coverslips with PC12 cells or membranes with pontine slice cultures were transferred into the recording chamber of an upright fluorescence microscope (DMLFSA, Leica Microsystems), superfused with artificial CSF [in mM: $\mathrm{NaCl}(125), \mathrm{KCl}(3), \mathrm{NaHCO}_{3}(24)$, $\mathrm{KH}_{2} \mathrm{PO}_{4}$ (1.25), $\mathrm{MgSO}_{4}$ (1.25), $\mathrm{CaCl}_{2}$ (2.5) and D-glucose (10) saturated with $95 \% \mathrm{O}_{2} / 5 \% \mathrm{CO}_{2}, \mathrm{pH} 7.3$, osmolality $\left.290 \mathrm{mOsm} / \mathrm{L}, 20^{\circ} \mathrm{C}\right]$ at a rate of $1 \mathrm{ml} \cdot \mathrm{min}^{-1}$. Patch pipettes (resistances of 4-7 M $\Omega$ ) were filled with internal solution [in mM: $\mathrm{K}$ Gluconate (130), $\mathrm{KCl}(10), \mathrm{NaCl}(10), \mathrm{MgCl}_{2}$ (2), HEPES (10), $\mathrm{Na}_{2} \mathrm{ATP}(2)$ and $\mathrm{Na}_{2} \mathrm{GTP}(0.2)$ ]. All membrane potentials were corrected for a junction potential of $13 \mathrm{mV}$. EGFP-expressing cells were identified using epifluorescence microscopy and then wholecell recordings were obtained under gradient contrast illumination (Dodt and Zieglgänsberger, 1990). Recordings were made in current clamp mode and current pulses were injected to examine the currentvoltage and current-spike frequency relationships (Axopatch 1D amplifier, Molecular Devices). Data were acquired and stored using Spike2 software (CED, Cambridge Electronic Design). The threshold for spike firing was determined as the point at which the rate of change of membrane potential exceeded $7.5 \mathrm{~V} / \mathrm{s}$ and all spike parameters were measured with reference to this point (using a custom written Spike2 script).

\section{Dorsal horn adenoviral vector injection}

The procedures for lumbar spinal injection of AVV have been described previously (Howorth et al., 2009). In brief, rats (130-200 g) were anesthetized (i.m. or i.p.) with ketamine $(5 \mathrm{mg} / 100 \mathrm{~g}$, Vetalar, Pharmacia) and medetomidine (30 $\mu \mathrm{g} / 100 \mathrm{~g}$, Domitor, Pfizer) until loss of paw withdrawal reflex. The animal was placed in a stereotaxic frame and core temperature was maintained at $37^{\circ} \mathrm{C}$ using a homeothermic blanket (Harvard Apparatus). Aseptic surgical techniques were used throughout.

The spinous processes of T13 and L1 were identified and a laminectomy performed to allow access to the spinal segments L4-5. Injections of AVV were made in the dorsal horn $400 \mu \mathrm{m}$ lateral to the midline and $500 \mu \mathrm{m}$ deep to the dorsal surface using a micro-capillary pipette (calibrated in $1 \mu \mathrm{l}$ intervals; Sigma), with a tip diameter of $20 \mu \mathrm{m}$ (see supplemental Fig. 1, available at www.jneurosci.org as supplemental material). Two pairs of bilateral injections (each $500 \mu \mathrm{m}$ apart in the rostrocaudal axis) of AVV $\left(500 \mathrm{nl} /\right.$ per injection of $3 \times 10^{10} \mathrm{TU} / \mathrm{ml} \mathrm{AVV}$ over $2 \mathrm{~min}$ ) were made into the L4-5 spinal segments. The dose of AVV administered was chosen to achieve maximal transduction of the NA neurons, based on our previous titration experiments balancing the efficacy of retrograde expression against the inflammatory response at the injection site triggered by higher viral titers (Howorth et al., 2009).

After injections, anesthesia was reversed with atipamezole $(0.1 \mathrm{mg} / 100$ g, i.p., Antisedan, Pfizer) and buprenorphine was given for pain relief (2 $\mu \mathrm{g} / 100$ g, s.c., Temgesic, Schering-Plough). Animals showed a rapid functional recovery from anesthesia and surgery and their movement appeared normal the following day. Rotarod testing before and after spinal AVV injection showed no significant difference in motor function in either the AVV-PRS-EGFP group $[210 \pm 21 \mathrm{~s}$ vs $191 \pm 32 \mathrm{~s}$ after injection $(n=7)$ ] or the AVV-PRS-hKir 2.1 group [201 \pm 18 s vs $178 \pm$ $22 \mathrm{~s}$ after injection $(n=6)$, paired $t$ test, not significant].

\section{Pain assays}

Animals were handled daily and habituated to the testing room, equipment, and observer. All experiments were done under observer-blinded conditions with concealment of the AVV identity.

Hargreaves' and von Frey testing. Animals had tests of both thermal and mechanical nociception before and after AVV administration and after induction of sensitization. The heat pain withdrawal latencies were measured for the hindpaw using the method described by Hargreaves et al. (1988). The infrared source was directed onto the plantar surface of the paw and the time to withdrawal recorded (Ugo Basile Plantar test). Each withdrawal value was the mean of 3 tests ( 5 min between tests). A $30 \mathrm{~s}$ cutoff value was used to terminate the test and avoid tissue damage. The punctate pressure withdrawal threshold was assessed using von Frey hairs (TouchTest, Linton Instruments) applied to the lateral edge of the 
plantar surface of the paw for $3 \mathrm{~s}$ or until paw withdrawal. Filaments were applied sequentially according to the up-down method (Dixon, 1980) to obtain a threshold value [after (Chaplan et al., 1994)] starting with the $6 \mathrm{~g}$ filament and with an upper cutoff of $26 \mathrm{~g}(\sim 10 \%$ of rat body weight, stiffer hairs simply lifted the hindpaw).

Hindpaw inflammation. Rats received bilateral lumbar spinal injections of AVV-PRS-hKir ${ }_{2.1}(n=7)$ or AVV-PRS-EGFP $(n=7)$. Ten days later they had complete Freund's adjuvant (CFA) injected subcutaneously to the plantar surface of the hindpaw (50 $\mu \mathrm{l}, 50 \mu \mathrm{g}$, Calbiochem) under brief Halothane anesthesia. This produced localized inflammation, edema and sensitization of the hindpaw [as previously described by Iadarola et al., (1988)] and resulted in an increase in paw thickness ( $4.0 \pm$ 0.1 to $5.1 \pm 0.2 \mathrm{~mm}(n=14)$, with no significant differences between AVV groups). The dose of CFA was chosen (based on previous experience, personal communication from Lucy Donaldson) to produce a moderate degree of sensitization to facilitate the detection of any hyperalgesic effects of AVV administration [after (Wei et al., 1999)]. Sensory testing (Hargreaves' and von Frey as above) was performed before AVV injection, immediately before CFA injection and again $2 \mathrm{~h}$ after injection. Subsequently the animals were killed for histology at $3 \mathrm{~h}$ post CFA injection.

Formalin testing. The nociceptive behavioral response to subcutaneous formalin was assessed (Dubuisson and Dennis, 1977) after bilateral lumbar spinal injections of AVV-PRS-hKir ${ }_{2.1}(n=15$ rats) or AVV-PRSEGFP $(n=16)$. Two weeks later, the animals underwent nociceptive testing and had either formalin (5\% neutral buffered, $n=22$ ) or $0.9 \%$ saline $(n=9)$ injected subcutaneously $(50 \mu$ l, $30 \mathrm{G}$ needle) on the dorsal surface of the right hindpaw. Rats were replaced in the testing chamber and the numbers of flinches and foot lifts were tallied over 1 min periods, initially every $2 \mathrm{~min}$ for the first $10 \mathrm{~min}$ and then every $5 \mathrm{~min}$ for the remainder of the $60 \mathrm{~min}$.

Animals were culled $2 \mathrm{~h}$ after the end of the observation period to allow optimal c-Fos expression and perfused with fixative $(n=6$ for control and $n=16$ for formalin test rats, protocol below). The lumbar spinal cord was removed with intact dorsal roots and ganglia to allow segmental identification. Spinal tissue was sectioned transversely on a freezing microtome ( $40 \mu \mathrm{m}$ sections) and 1 section in 4 was processed for c-Fos IHC (see below). The spinal c-Fos expression was quantified for each animal by tallying the positive neurons from 10 nonsequential, transverse spinal cord sections $(40 \mu \mathrm{m})$ from L3-5 with the greatest numbers of c-Fos-positive nuclei. Counts were subdivided into three regions corresponding to the superficial (SDH, laminas I-II) and deep dorsal horn (DDH, laminas III-VI) and the ventral horn (VH, laminas VII-IX, excluding area X) with reference to Paxinos and Watson (2005). The rostrocaudal distribution of the c-Fos expression was quantitated by averaging the number of c-Fos-positive cells per section in dorsal and ventral horns from each spinal cord segment from L2-L6.

Spared nerve injury. To produce a model of neuropathic hind limb pain the spared nerve injury (SNI) method was used (Decosterd and Woolf, 2000). Rats $(n=13)$ were anesthetized with ketamine and medetomidine until loss of paw withdrawal. The sciatic nerve was exposed at the mid-thigh level and its branches the tibial, common peroneal, and sural nerves were identified. The tibial and peroneal nerves were ligated with 5-0 silk and cut, paying particular attention to avoid damage to the sural nerve.

Animals had sensory testing (Fig. 5, see schedule) on consecutive days before AVV injection, $1 \mathrm{~d}$ before SNI and then on days 4, 7, 10 and 14 after SNI. Mechanical allodynia was assessed using von Frey hairs (as described previously) to obtain a threshold value. Cold allodynia was tested by the application of an acetone drop to the lateral aspect of the hindpaw. A withdrawal/flinch was scored as a positive response and the duration of paw lift was measured for each response (with an upper cutoff of $1 \mathrm{~min}$ ). Animals were culled on day 15 (post $\mathrm{SNI}$ ) and brain tissue was processed (see below) to confirm successful AVV transduction of the pontospinal NAergic neurons (by detection of EGFP).
Table 1. Antibodies

\begin{tabular}{lllll}
\hline & Dilution & Species or tag & Source & Code (batch) \\
\hline $\begin{array}{llll}\text { Primaries } \\
\text { DBH }\end{array}$ & $1: 5000$ & Mouse & Millipore & MAB308(24120144) \\
C-Fos & $1: 2000$ & Rabbit & Santa Cruz & Sc-52 (H0105) \\
GFP & $1: 4000$ & Rabbit & Invitrogen & A11122 (56884A) \\
hKir $_{2.1}$ & $1: 200$ & Rabbit & Alomone & APC-026 (AN 02) \\
Secondaries $^{a}$ & & & & \\
Anti-mouse & $1: 100$ & AMCA & Jackson & 715-156-150 \\
Anti-rabbit & $1: 500-1000$ & Biotinylated & Jackson & 711-066-152 \\
\hline${ }^{a}$ Raised in donkey. & & & &
\end{tabular}

\section{Rotarod testing}

To assess motor function after spinal injection of AVV animals had rotarod testing ( $n=13$, from SNI group). After training and habituation to the rotarod ( 2 sessions, animals were trained to remain on the rotarod for $40 \mathrm{~s}$ at $16 \mathrm{rpm}, 5 \mathrm{~min}$ between each session), animals were tested (maximum duration $5 \mathrm{~min}$, speed increasing from 4 to 40 r.p.m. over $5 \mathrm{~min}$ ) both before and $6 \mathrm{~d}$ after AVV injection. The length of time the animals remained on the rotarod was recorded.

\section{Tissue fixation}

Rats were killed (at 14 d, unless otherwise stated) with an overdose of pentobarbital (20 mg/100 g, i.p., Euthatal, Merial Animal Health) and perfused transcardially with $0.9 \% \mathrm{NaCl}(1 \mathrm{ml} / \mathrm{g})$ followed by $4 \%$ formaldehyde (Sigma) in $0.1 \mathrm{~m}$ phosphate buffer $(\mathrm{pH} 7.4,1 \mathrm{ml} / \mathrm{g})$. The brain and spinal cord (including dorsal root ganglion and spinal roots) were removed and postfixed for $2 \mathrm{~h}$ before overnight cryoprotection in $30 \%$ sucrose. The attached dorsal roots and ganglia enabled identification of lumbar regions (L2-6) and confirmation of correct injection targeting to $\mathrm{L} 4-5$ segments (failures were excluded from analysis). Coronal tissue sections were cut at $40 \mu \mathrm{m}$ intervals using a freezing microtome and either serially mounted or left free floating for fluorescence IHC.

\section{Immunohistochemistry}

Tissue sections were washed $(\times 3)$ in PBS and permeabilized in $50 \%$ ethanol for $30 \mathrm{~min}$ before further washing. The tissue was incubated with primary antibodies against Dopamine $\beta$-hydroxylase (DBH), hKir ${ }_{2.1}$, c-Fos or EGFP [for details, see Table 1 and the study by Howorth et al. (2009)] in PBS with 5\% horse serum (HS), 0.3\% Triton X-100, and $0.01 \%$ sodium azide for $24-72 \mathrm{~h}$ at $5^{\circ} \mathrm{C}$. Mounted sections were kept in a humidified chamber (RA Lamb) and free-floating sections were continuously agitated. After further washing, sections were incubated overnight with either conjugated or biotinylated secondary antibodies (see Table 1) and diluted 1:500-1000 in PBS with 2\% HS and 0.3\% Triton. Sections were washed and incubated with Streptavidin Cy3 (1:1000 in PBS, Sigma) for $4 \mathrm{~h}$ before a final wash. Negative controls were routinely run by omitting primary antibodies. The specificity of labeling was verified by preincubation with either control antigen epitope peptides $\left(\mathrm{hKir}_{2.1}-\mathrm{in}\right.$ tracellular, C-terminal amino acids 392-410, 1:200, Alomone Labs APC026; c-Fos N terminus peptide amino acids 3-16, 1:10,000, sc-52P, Santa Cruz Biotechnology) or with slices of adrenal medulla [DBH, after

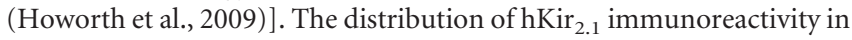
rat forebrain (in particular the piriform cortex and hippocampus) was similar to that previously reported (Karschin et al., 1996; Howe et al., 2008).

\section{Cell counts}

After in vivo spinal transduction with AVVs, successful retrograde expression was confirmed by post hoc examination of pontine tissue for EGFP-positive neurons in the NAergic cell groups (A5-A7). Cell counts were determined for representative groups of AVV-PRShKir $_{2.1}$ and AVV-PRS-EGFP animals ( $n=4$ /group) to compare the efficacy of transduction and the distribution of labeled pontospinal NAergic neurons. Neuronal somata were counted as being present in the section only if their nucleus was visible and all counts were Abercrombie corrected, as previously described (Howorth et al., 2009). 
A
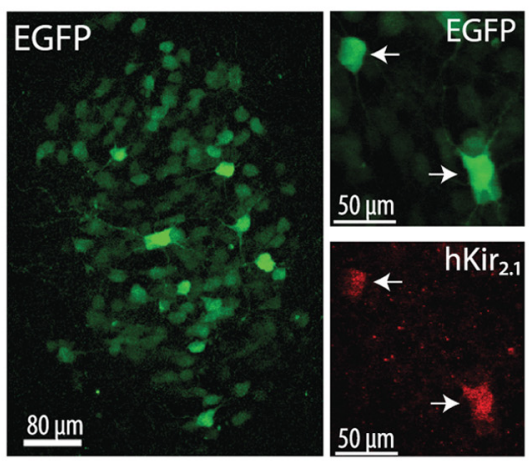

$E$

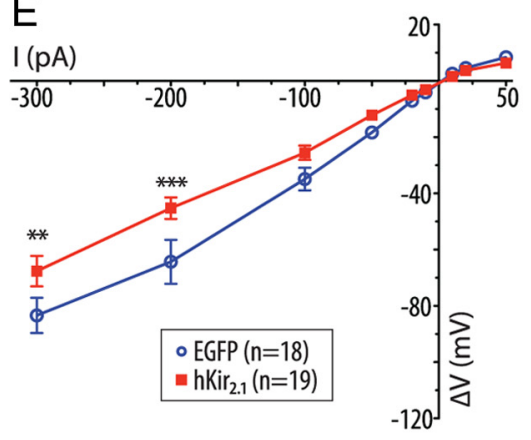

$B$

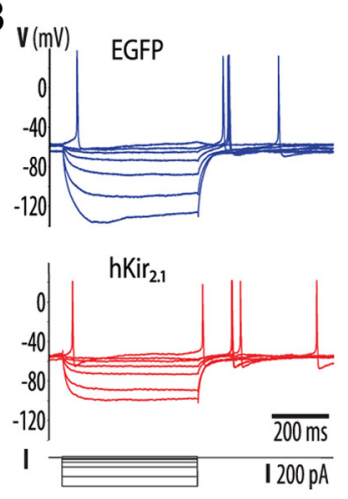

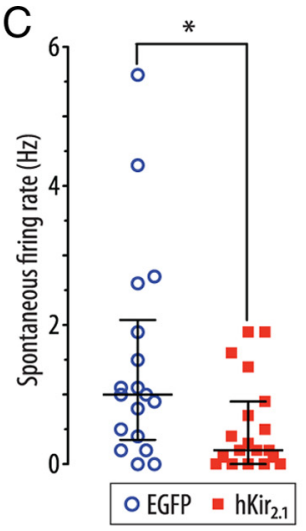

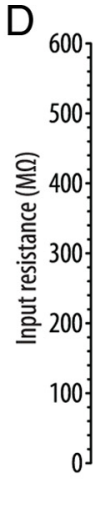

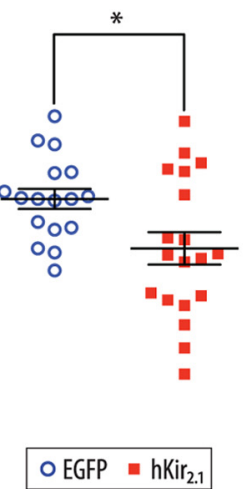

$\mathrm{F}$

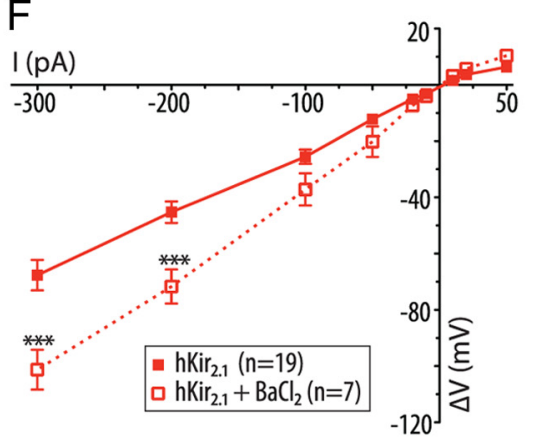

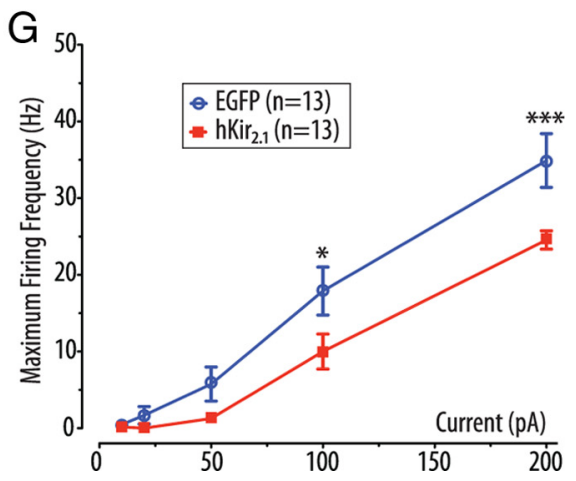

Figure 1. Expression of hKir ${ }_{2.1}$ inhibits locus ceruleus neurons in vitro. A, Pontine slice culture (from P7 rat) after transduction with AVV-PRS-EGFP, showing EGFP expression in neurons of the LC. Right panels show LC neurons from a pontine slice culture transduced with AVV-PRS-EGFP and AVV-PRS-hKir ${ }_{2.1}$ (ratio 2:1) showing colocalization of EGFP and hKir ${ }_{2.1}$-immunoreactivity (white arrows indicate hKir ${ }_{2.1}$-positive neurons). B, Current clamp recordings from representative transduced LC neurons (control or hKir ${ }_{2.1}$-expressing) showing overlaid membrane potential responses to injected current pulses $(+10$ to $-300 \mathrm{pA}) . \mathrm{C}, \mathrm{LC}$ neurons transduced with AVV-PRS-hKir ${ }_{2.1}$ had a reduced frequency of spontaneous action potential discharge (median 0.2 vs $1.0 \mathrm{~Hz}$, interquartile range marked, Mann-Whitney test, $\left.{ }^{*} p<0.05\right)$. D, Expression of hKir ${ }_{2.1}$ in $\mathrm{LC}$ neurons lowered their input resistances $\left(256 \pm 23 \mathrm{vs} 327 \pm 14 \mathrm{M} \Omega\right.$, unpaired $t$ test, $\left.{ }^{*} p<0.05\right)$. $\boldsymbol{E}$, Examination of the current-voltage relationship showed that $\mathrm{LC}$ neurons expressing hKir ${ }_{2.1}$ had marked inward rectification (two-way ANOVA, ${ }^{* *} p<0.01$ and ${ }^{* * *} p<0.001$ ). $\boldsymbol{F}$, This inward rectification was blocked by superfusion of barium $\left(100 \mu \mathrm{m}\right.$, two-way ANOVA, $\left.{ }^{* * *} p<0.001\right)$. G, Neurons were hyperpolarized to $-75 \mathrm{mV}$ (by DC current injection) to stop spontaneous action potential discharge. The maximum spike frequency response to injected current pulses $(10-200 \mathrm{pA}, 500 \mathrm{~ms})$ was plotted showing that the $\mathrm{L} C$ neurons expressing hKir ${ }_{2.1}$ were less excitable $\left({ }^{*} p<0.05\right.$ and ${ }^{* * *} p<0.001$, repeated measures ANOVA).

\section{Photomicrography}

Representative images were taken on either a Zeiss Axioskop 2 with Axiocam HRC (Carl Zeiss) using appropriate excitation-emission filter sets (EGFP, \#10; Cy3, \#15) or on a Leica DMRBE and TCSNT confocal microscope (Leica). Confocal image stacks were obtained at $0.5-4 \mu \mathrm{m}$ steps for Cy3 (excitation $543 \mathrm{~nm}$, emission $607 \mathrm{~nm}$ ) and EGFP (excitation $488 \mathrm{~nm}$, emission 500-530 nM), and each frame was averaged four times, to reduce background noise. Final images are maximum intensity projections, unless otherwise stated. Images were initially processed using respective company software, and prepared for presentation using Adobe Photoshop CS3 with optimization of contrast/brightness as required and addition of annotation.

Analysis

All data are presented as mean \pm SEM or median (interquartile range), as appropriate. The normality of data was assessed using the D'Agostino-Pearson test. Subsequent statistical testing was undertaken using paired and unpaired $t$ tests, one and two way ANOVA (with Bonferroni's post tests) and Mann-Whitney tests as appropriate. Data were analyzed using Prism 5 (Graphpad), and differences were considered significant at $p<0.05$.

\section{Results}

Functional expression of $\mathrm{hKir}_{2.1}$ in a catecholaminergic cell line

Whole-cell current clamp recordings were made from EGFPpositive PC12 cells transfected with either PRS-hKir ${ }_{2.1}$ or PRSEGFP (control) plasmid DNA. Cells expressing hKir $_{2.1}$ had a hyperpolarized resting membrane potential compared with control cells $[-68 \pm 2 \mathrm{mV}(n=16) \mathrm{vs}-56 \pm 2 \mathrm{mV}(n=21), p<$ 0.01 , one-way ANOVA], which was returned to the control level by the addition of barium to the perfusate $\left(100 \mu \mathrm{M} \mathrm{BaCl}{ }_{2}\right)$. The injection of hyperpolarizing current pulses showed the expression of hKir ${ }_{2.1}$ was associated with a marked inward rectification that was also blocked by barium $(100 \mu \mathrm{M})$ (supplemental Fig. 2, available at www.jneurosci.org as supplemental material) as would be anticipated if it were a consequence of functional hKir $_{2.1}$ expression (Kubo et al., 1993; Johns et al., 1999).

Expression of $\mathrm{hKir}_{2.1}$ inhibits locus ceruleus neurons in vitro Transduction of pontine slice cultures with AVV-PRS-EGFP alone or with AVV-PRS-hKir 2.1 allowed visualization of EGFPpositive neurons in the LC (clearly identifiable by its dorsal position and dense packing of EGFP-positive NAergic neurons) (Fig. 1A). After transduction with AVV-PRS-hKir ${ }_{2.1}$, IHC showed expression of $\mathrm{hKir}_{2.1}$ in EGFP-positive neurons within the LC (Fig. 1A); notably, hKir 2.1 was not detectable in LC neurons that were EGFP negative (cultures from 3 rats) or in cultures transduced with AVV-PRS-EGFP.

Whole-cell current clamp recordings of transduced LC neurons in slice cultures showed characteristic patterns of activity with spontaneous firing of action potentials (with long duration, a prominent inflection on repolarization and a large 
Table 2. Comparison of membrane properties and action potential parameters of LC neurons in slice culture transduced with AVV-PRS-EGFP or AVV-PRS-hKir ${ }_{2.1}$

\begin{tabular}{lcc}
\hline Parameter & AVV-PRS-EGFP $(n=18)$ & AVV-PRS-hKir $_{2.1}(n=19)$ \\
\hline Membrane potential $(\mathrm{mV})$ & $-58.5(-57.2$ to -64.0$)$ & $-56.6(-46.5$ to -58.6$)$ \\
Input resistance $(\mathrm{M} \Omega)$ & $327 \pm 14$ & $256 \pm 23^{*}$ \\
Spontaneous firing rate $(\mathrm{Hz})$ & $1.0(0.35$ to 2.1$)$ & $0.2(0.0 \text { to } 0.9)^{*}$ \\
Spike threshold $(\mathrm{mV})$ & $-37 \pm 1.4$ & $-35 \pm 2.4$ \\
Spike amplitude $(\mathrm{mV})$ & $60 \pm 3$ & $56 \pm 4$ \\
Spike duration $(1 / 3 \mathrm{max}, \mathrm{ms})$ & $5.3(3.5$ to 7.2$)$ & $5.2(3.7$ to 7.6$)$ \\
AHP amplitude $(\mathrm{mV})$ & $23(18$ to 24$)$ & $23(21$ to 26$)$ \\
AHP duration $(\mathrm{ms})$ & $124(81$ to 181$)$ & $182(98$ to 250$)$
\end{tabular}

Data quoted as mean \pm SEM or median (interquartile range) and significance assessed using unpaired $t$ test or Mann-Whitney test as appropriate. ${ }^{*} p<0.05$.

$t$ test, $p<0.05$ ) (Fig. 1D, Table 2). Expression of hKir ${ }_{2.1}$ increased the inward rectification seen on hyperpolarizing current injection (Fig. $1 E$ ), which was blocked by the addition of barium to the perfusate $\left(\mathrm{BaCl}_{2}, 100 \mu \mathrm{M}, p<0.01\right.$, two-way ANOVA, $\left.n=7\right)$ (Fig. $1 F$ ). Barium superfusion increased the input resistance of LC neurons transduced with AVV-PRS-hKir ${ }_{2.1}(243 \pm 28$ to $376 \pm 68 \mathrm{M} \Omega, n=7, p<0.05$, paired $t$ test) but not those transduced with AVV-PRS-EGFP $(366 \pm 28$ to $392 \pm 118 \mathrm{M} \Omega$, $n=4$, NS, paired $t$ test). No difference was seen in membrane potential or action potential parameters in neurons transduced with AVV-PRS-hKir ${ }_{2.1}$ compared with AVV-PRS-EGFP (table 2 ). To test for changes in excitability neurons were hyperpolarized with DC current injection to $-75 \mathrm{mV}$ (to stop spontaneous spiking) and then depolarizing current pulses were injected (10-200 pA, $500 \mathrm{~ms}$ ). LC neurons transduced with AVV-PRShKir $_{2.1}$ were significantly less excitable with a lower maximum firing frequency in response to a given current pulse (Fig. $1 G)$.

\section{Transduction of pontospinal NAergic} neurons in vivo with AVV-PRS-hKir ${ }_{2.1}$ Intraparenchymal injection of either AVV-PRS-EGFP or AVV-PRS-hKir ${ }_{2.1}$ to the lumbar dorsal horn (L4-5) retrogradely transduced pontine NAergic neurons as indicated by the presence of EGFP fluorescence (Fig. 2). The numbers of transduced pontine neurons and pattern of retrograde labeling was similar to that which we previously reported (Howorth et al., 2009) and depended on the intraparenchymal administration of AVV, as intentional control intrathecal injection of AVV did not transduce any neurons in the pons (nor spinal cord, $n=2$ ). There was no difference in the total number of neurons transduced with AVV-PRShKir $_{2.1}$ compared with AVV-PRS-EGFP $(162 \pm 46$ vs control $146 \pm 34, n=4$ rats/group, one-way ANOVA, NS), with a comparable distribution across the LC $(123 \pm 31$ vs control $112 \pm 28)$, A5 (23 \pm 13 vs control $22 \pm 6$ ), and A7 ( $16 \pm 4$ vs control $11 \pm 2$ ) pontine cell groups (Fig. $2 B)$. After transduction with AVV-PRS$\mathrm{hKir}_{2.1}$, only pontine NAergic neurons expressing EGFP were immunopositive for hKir $_{2.1}$ (Fig. 2C). In contrast, no NAergic neurons showed $\mathrm{hKir}_{2.1}$-immunoreactivity in animals transduced with AVV-PRSEGFP (nor in naive animals). Expression of EGFP and $\mathrm{hKir}_{2.1}$ was detectable 4 weeks after transduction (the longest time point examined) indicating that AVV gene ex-

afterhyperpolarization) (Fig. $1 B$ ) often driven by underlying oscillations in membrane potential (Williams et al., 1984; Williams and Marshall, 1987). Neurons transduced with AVV-PRS-hKir ${ }_{2.1}$ showed a lower frequency of spontaneous spike firing [median $0.2(0-0.9), n=19$ vs $1.0(0.35-2.1) \mathrm{Hz}, n=18, p<0.05$, Mann-Whitney test] (Fig. $1 C$ ) and reduced input resistance $(256 \pm 23[n=19]$ vs control $327 \pm 14 \mathrm{M} \Omega[n=17]$, unpaired pression persisted at least for the duration of the experiments reported below.

$\mathrm{hKir}_{2.1}$ expression in pontospinal NAergic neurons causes hyperalgesia

An initial assessment of the effect of AVV transduction on baseline measures of thermal and mechanical nociception 
showed evidence of thermal hyperalgesia in the AVV-PRS-hKir ${ }_{2.1}$ group. Hargreaves' hindpaw withdrawal latency decreased significantly after transduction of NA neurons with $\mathrm{hKir}_{2.1}(16 \pm 1$ vs $13 \pm$ $1 \mathrm{~s}$ after AVV (10 d) respectively, $n=11$, $p=0.02)$ but not after transduction with EGFP ( $14 \pm 1$ vs $12 \pm 1 \mathrm{~s}, n=8$, NS). In contrast there was no evidence of any accompanying mechanical sensitization (assessed with von Frey hairs). To explore this further we used the CFA inflammatory pain model and repeated the tests of mechanical and thermal nociception in two groups of AVV transfected animals ( $n=7$ /group).

As before, the AVV-PRS-hKir 2.1 group showed thermal hyperalgesia after vector administration $\left[\mathrm{hKir}_{2.1} 17 \pm 2\right.$ vs $14 \pm 1 \mathrm{~s}$ $(p<0.05)$ vs EGFP $16 \pm 1$ vs $16 \pm 1 \mathrm{~s}$ (NS) (Fig. 3A)] without any change in mechanical thresholds $\left[\mathrm{hKir}_{2.1} 26 \pm 0 \mathrm{~g}\right.$ vs $26 \pm 1 \mathrm{~g}$ (NS) and EGFP $23 \pm 2 \mathrm{~g}$ vs $21 \pm$ $3 \mathrm{~g}$ (NS) (Fig. 3C)]. To take account of the altered thermal nociception after AVV administration in the AVV-PRS-hKir ${ }_{2.1}$ group, the change in hindpaw thermal withdrawal after CFA was compared against the contralateral hindpaw. Injection of CFA produced thermal sensitization in both groups of animals [difference after CFA: $\operatorname{hKir}_{2.1}-10 \pm 1 \mathrm{~s}, p<0.001$ and EGFP $-6 \pm 2 s, p<0.01$, two-way rmANOVA with post hoc Bonferroni tests (Fig. 3B)]. Interestingly, the AVV-PRShKir ${ }_{2.1}$ group, which started from an already sensitized state, showed almost a twofold greater decrease in thermal withdrawal latency after CFA $(-8.0$ vs $-4.7 \mathrm{~s}$, respectively). In contrast, although the mechanical withdrawal threshold was also significantly lowered after CFA $\left[\mathrm{hKir}_{2.1}\right.$, $26 \pm 1$ to $21 \pm 2 \mathrm{~g}, p<0.05$ vs EGFP, $21 \pm$ 3 to $14 \pm 3 \mathrm{~g}, p<0.01$ (Fig. $3 C$ )], the magnitude of this change was similar in both groups.

To further characterize this hyperalgesic effect, we studied the effect of inhibition of pontospinal NA neurons in the formalin test (Dubuisson and Dennis, 1977) to see whether there was any alteration in nociceptive behavioral responses and spinal c-Fos expression. Both groups of animals (hKir ${ }_{2.1}$ and EGFP) showed characteristic biphasic nociceptive behavioral responses to hindpaw formalin testing. Animals transduced with AVV-

PRS-hKir ${ }_{2.1}$ showed significantly more flinches/paw lifts than the AVV-PRS-EGFP group in response to formalin [(Fig. $4 A)$ phase I, $113 \pm 10$ vs control, $86 \pm 5, p<0.05$ and phase II, $130 \pm 11$ vs control $104 \pm 7, p<0.05 n=11 /$ group]. This was mirrored by an increased intensity of c-Fos expression in the lumbar spinal cord after formalin testing in the AVV-PRS-hKir ${ }_{2.1}$ group [(Fig. 4B,C) $\left.-7.0 \mathrm{~g} \mathrm{vs} \mathrm{hKir}_{2.1},-5.1 \mathrm{~g}\right)$.
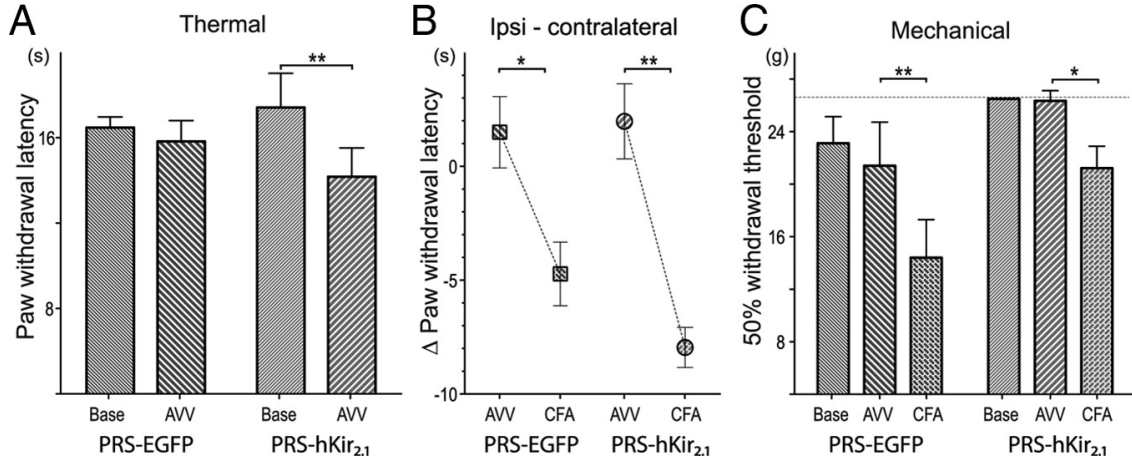

Figure 3. Inhibition of pontospinal NAergic neurons causes thermal but not mechanical hyperalgesia. To examine the effect of inhibition of pontospinal NA neurons in a sensitized state we used the CFA inflammatory pain model in two groups of animals that had been transfected with AVV 10 dearlier ( $n=7 /$ group). $A$, Animals transduced with AVV-PRS-hKir ${ }_{2.1}$ showed thermal hyperalgesia on Hargreaves' testing [hKir ${ }_{2.1} 17 \pm 2$ vs $\left.14 \pm 1 \mathrm{~s}(p<0.05)\right]$ before CFA injection, this was not seen in the control animals (EGFP $16 \pm 1$ vs $16 \pm 1 \mathrm{~s}$ (NS)] (two-way rmANOVA with Bonferroni post tests). $\boldsymbol{B}$, To account for the change in baseline thermal nociception in the AVV-PRS-hKir ${ }_{2.1}$ group, the changes in ipsilateral hindpaw withdrawal latency after CFA was compared relative to the contralateral hindpaw. Injection of CFA produced thermal sensitization in both groups of animals [difference after CFA: EGFP, $-6 \pm 2 \mathrm{~s}, p<0.01$ vs hKir $2.1,-10 \pm 1 \mathrm{~s}, p<0.001$ (two-way rmANOVA with post hoc Bonferroni tests)]. Strikingly, the AVV-PRS-hKir ${ }_{2.1}$ group, which started from an already sensitized state, showed almost a twofold greater decrease in thermal withdrawal latency after CFA (hKir $2.1-8.0$ s vs EGFP -4.7 s). C, Transduction with AVV had no significant effect on the mechanical withdrawal thresholds in either group. After CFA injection, both groups of animals showed significant sensitization (EGFP, $p<0.01 ; \mathrm{hKir}_{2.1}, p<0.05$ ), although the magnitude of this change was similar in both groups (EGFP,
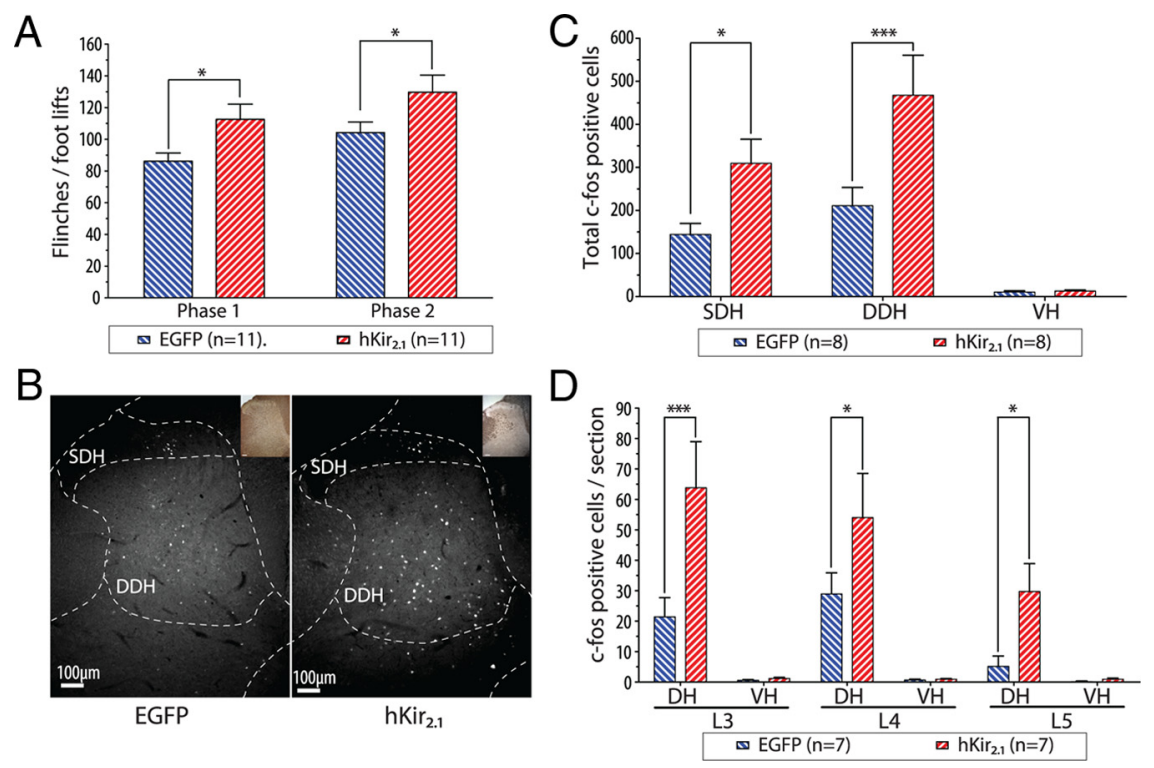

Figure 4. Inhibition of pontospinal NAergic neurons causes hyperalgesia and increased spinal c-Fos in the formalin test. $A$, Rats transduced with either AVV showed typical biphasic nocifensive behavioral responses to the injection of formalin. Transduction with AVV-PRS-hKir ${ }_{2.1}$ produced hyperalgesia as indicated by an increase in the numbers of flinches/foot lifts in both phase I and II of the formalin test (two-way ANOVA, ${ }^{*} p<0.05, n=11 /$ group). $\boldsymbol{B}$, Formalin test-evoked expression of c-Fos in the superficial and deep laminae of the lumbar spinal cord (shown here at L4). There was a marked increase in the numbers of c-Fos-positive cells in animals transduced with AVV-PRS-Kir ${ }_{2.1}$.C, Transduction with AVV-PRS-hKir ${ }_{2.1}$ increased the numbers of formalin test-evoked c-Fos-positive cells in both the superficial and deep lumbar dorsal horn [compared with animals transduced with AVV-PRS-EGFP ( $n=8 /$ group), two-way ANOVA, $\left.{ }^{*} p<0.05,{ }^{* * *} p<0.001\right]$. D, The AVV-PRS-hKir 2.1 group also showed a significant increase in the numbers of c-Fos-positive cells in the dorsal horn across each of the spinal segments L3-L5 (two-way ANOVA, ${ }^{*} p<0.05$ and ${ }^{* * *} p<0.001, n=7 /$ group).

superficial dorsal horn $310 \pm 56$ vs EGFP $144 \pm 26, p<0.05$ and deep dorsal horn $468 \pm 93$ vs EGFP $211 \pm 42, p<0.01$, c-Fospositive profiles/10 sections, $n=8$ /group]. This increased c-Fos expression in the AVV-PRS-hKir ${ }_{2.1}$ group was seen across lumbar segments L3-L5 (Fig. 4D), which receive sensory inputs from 


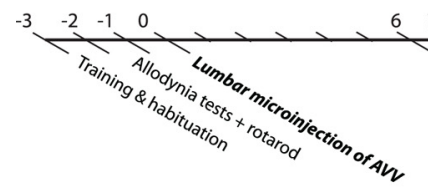

$67,-11$

B

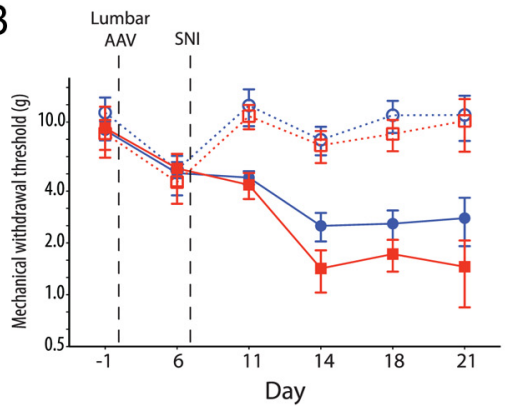

$11>14$

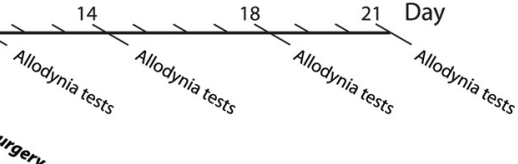

$\mathrm{C}$

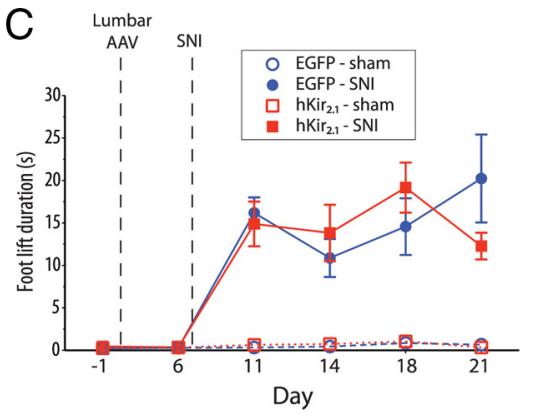

Figure 5. AVV-PRS-hKir ${ }_{2.1}$ does not increase allodynia in spared nerve injury model. $\boldsymbol{A}$, To assess the effect of transduction with AVV-PRS-hKir 2.1 on the development of the signs of neuropathic pain, animals received lumbo-spinal injection of either AVV-PRShKir $_{2.1}$ or AVV-PRS-EGFP 1 week before SNI. Each group was then followed for 2 weeks and assessed for the development of mechanical and cold allodynia. $\boldsymbol{B}, \boldsymbol{C}$, After spinal AVV administration, both groups of SNI animals developed significant $(\boldsymbol{B})$ mechanical allodynia (von Frey hair threshold) and (C) cold allodynia (acetone drop induced paw withdrawal). Transduction of the pontospinal NAergic neurons with AVV-PRS-hKir ${ }_{2.1}$ did not significantly alter the expression of mechanical or cold allodynia compared with AVV-PRS-EGFP (two-way rmANOVA).

the hindpaw, but not in segments L2 or L6 that showed negligible induction of c-Fos in either group of animals ( $n=7$ /group).

hKir $_{2.1}$ expression in pontospinal NAergic neurons does not alter neuropathic allodynia

Spared nerve injury (SNI) (Decosterd and Woolf, 2000) produced behavioral signs of hindlimb sensitization [mechanical and cold allodynia (Fig. 5)] in rats that had received prior spinal cord injections of either AVV-PRS-EGFP or AVV-PRS-hKir ${ }_{2.1}$. There was no significant difference between the vector treated groups (Fig. 5) in either mechanical allodynia (von-Frey threshold $1.4 \pm 0.4 \mathrm{~g}, n=6 \mathrm{vs}$ control $2.5 \pm 0.5 \mathrm{~g}, n=7$, day 7 post SNI) or in cold allodynia (duration of paw lift $14 \pm 3 \mathrm{~s}, n=6 \mathrm{vs}$ control $11 \pm 2 \mathrm{~s}, n=7$, day 7 post SNI) or at any other time point examined.

\section{Discussion}

We have developed a genetic strategy to alter the excitability of NAergic neurons projecting to the lumbar spinal cord. This has been achieved using an AVV to express a potassium channel $\left(\mathrm{hKir}_{2.1}\right)$ selectively in pontospinal NAergic neurons. Expression of $\mathrm{hKir}_{2.1}$ decreased the excitability of NAergic neurons in vitro and reduced their spontaneous firing frequency. In vivo expression of hKir ${ }_{2.1}$ in $\sim 150$ pontospinal NAergic neurons produced selective thermal hyperalgesia in tests of evoked nociception (in naive and CFA inflamed hindpaws) and increased nocifensive behaviors in the formalin test accompanied by increased c-Fos expression in the dorsal horn of the spinal cord. These data provide functional evidence for the tonic involvement of pontospinal NAergic neurons in the regulation of specific nociceptive behaviors and identify the retrograde transduction approach using viral vectors as a viable strategy to alter their excitability and affect nociceptive processing in vivo.

AVV can retrogradely transduce CNS cells (Akli et al., 1993; Ridoux et al., 1994) including pontospinal neurons (Liu et al., 1997b). We have refined this technique to target pontospinal catecholaminergic neurons using the cell-specific PRSx8 promoter

developed by Hwang et al. (2001). This approach has good efficiency for retrograde transduction of NAergic neurons (Lonergan et al., 2005; Howorth et al., 2009) and injection of this AVV to the lumbar dorsal horn identifies $\sim 150$ neurons (mostly in LC with the remainder in A7 and A5).

The LC projects to most of the neuroaxis and there has been debate over which of the pontine NAergic cell groups provides the predominant innervation to the dorsal horn (Guyenet, 1980; Westlund et al., 1983; Loughlin et al., 1986; Fritschy and Grzanna, 1990; Burnett and Gebhart, 1991; Clark and Proudfit, 1991a,b; West et al., 1993) with evidence of differences between rat strains and stock (Fritschy and Grzanna, 1990; Clark and Proudfit, 1991a; Sluka and Westlund, 1992). Therefore, to circumvent these issues, we retrogradely targeted just the NAergic neurons with terminals in the lumbar dorsal horn with the objective of modulating the activity of the neurons regulating spinal sensory transmission (minimizing interference with the other roles of the NAergic system).

Since the original description of the use of $\mathrm{hKir}_{2.1}$ to inhibit neurons in vitro (Johns et al., 1999) several studies have used hKir $_{2.1}$ to suppress neuronal activity in vivo (Yu et al., 2004; Duale et al., 2007; Mizuno et al., 2007). We chose hKir ${ }_{2.1}$ to manipulate excitability because it is not normally present in pontine NAergic neurons (Karschin et al., 1996) and as they exhibit tonic firing (Guyenet, 1980) we expected to be able to demonstrate a functional phenotype. The expression of $\mathrm{hKir}_{2.1}$ in NAergic neurons in vitro produced the anticipated barium-sensitive inward rectification (Kubo et al., 1993) and reduced the spontaneous discharge rate by $\sim 80 \%$, comparable to that reported to produce changes in axonal mapping (Yu et al., 2004; Mizuno et al., 2007). We have previously shown that $\mathrm{hKir}_{2.1}$-mediated inhibition of NAergic A2 neurons in vivo produces functional alterations in blood pressure and fluid balance regulation (Duale et al., 2007).

Inhibition of pontospinal NAergic neurons produced a modality-specific hyperalgesia, supporting the hypothesis that these neurons are a component of the endogenous analgesic system (Jones, 1991; Millan, 1997, 2002; Pertovaara, 2006). Acute stimulation of the LC or A7 produces potent analgesic effects (Jones and Gebhart, 1986a; Miller and Proudfit, 1990; Yeomans et al., 1992; West et al., 1993; Holden et al., 1999) that are reversed by intrathecal administration of $\alpha 2$-adrenergic antagonists. This is mediated by both a direct hyperpolarizing action and a presynaptic inhibition of afferent input (North and Yoshimura, 1984; Sonohata et al., 2004). Thus, there is a well defined neural circuit for descending NAergic control of spinal nociceptive transmission.

Several subtractive approaches have been used to examine the functional role of the NAergic neurons in regulating nociception in vivo including intrathecal $\alpha 2$-antagonists (Sagen and Proudfit, 1984; Sugimoto et al., 1986; Liu et al., 1997a; Omote et al., 1998; Wei and Pertovaara, 2006), electrical ablation of pontine NAergic nuclei (Tsuruoka and Willis, 1996), targeted chemical neuroablation (Fasmer et al., 1986; Martin et al., 1999; Jasmin et al., 2003) or genetic knock-out studies of the $\alpha 2$-adrenoceptor (Stone et al., 1997) or DBH (Jasmin et al., 2002). We have built 
on this foundation using a viral vector to produce a neuroanatomically focused genetic manipulation to alter the excitability of the pontospinal NAergic neurons projecting to the lumbar dorsal horn.

We show that inhibition of pontospinal NAergic neurons produces thermal hyperalgesia, in agreement with previous studies using chemical ablation (Fasmer et al., 1986; Martin et al., 1999 ), intrathecal administration of $\alpha 2$-adrenoceptor antagonists (Sagen and Proudfit, 1984) and gene knock out to upregulate (Bohn et al., 2000) or downregulate (Jasmin et al., 2002) NAergic function. The NAergic-regulation of nociceptive thresholds exhibits sensory modality specificity, as we found no alteration in mechanical nociception [like Jasmin et al. (2002)]. This change in thermal nociception indicates a tonic influence of the NAergic system on nociceptive processing.

Inhibition of pontospinal NAergic neurons exaggerated the nocifensive pain behaviors displayed during the formalin test. This was associated with increased c-Fos expression in the superficial and deep dorsal horn, indicating a heightened spinal responsiveness to noxious inputs. The formalin test has been shown to activate pontospinal NAergic neurons (Howorth et al., 2009) and to increase the level of spinal NE (Omote et al., 1998). Intrathecal administration of $\alpha 2$-antagonists augments the formalin response (Omote et al., 1998), increases the excitation of dorsal horn neurons (Green et al., 1998) and interruption of the descending monoaminergic pathways increases formalin-evoked spinal c-Fos expression (Liu et al., 1997a). These findings indicate that the NAergic endogenous analgesic system is recruited during the formalin test, acting at a spinal level to suppress the nociceptive signal [also noted in inflammatory pain models (Tsuruoka and Willis, 1996; Mansikka et al., 2004)]. It is therefore surprising that NAergic ablation studies have reported contrary effects on formalin-induced behaviors with hyperalgesia, hypoalgesia and no change (Fasmer et al., 1986; Martin et al., 1999; Jasmin et al., 2003). This may be because of different degrees of compensation for the ablation or because of the variable loss of NAergic neurons and projections to CNS sites after rostral toxin spread in the CSF [documented by Jasmin et al. (2003)]. This illustrates a potential advantage inherent in our selective vector approach that restricts expression of $\mathrm{hKir}_{2.1}$ to only those NAergic neurons with terminals in the lumbar dorsal horn.

Expression of $\mathrm{hKir}_{2.1}$ in the pontospinal NAergic neurons before SNI did not have a demonstrable hyperalgesic effect. A similar lack of efficacy in neuropathic pain models has been reported by studies using ablation of NA neurons (Li et al., 2002) or intrathecal $\alpha 2$-antagonists (Xu et al., 1999). However, a longer-term ablation study showed a transitory increase in mechanical sensitization after nerve ligation that resolved after $120 \mathrm{~d}$ (Jasmin et al., 2003). These authors suggested that the discrepancy between their findings and those of previous studies may have been because of a "floor" effect making it difficult to detect further sensitization in allodynic hindpaws (their animals had relatively moderate sensitization). Along the same lines, in nerve-injured animals that did not exhibit a neuropathic phenotype, blockade of spinal $\alpha 2$-receptors unmasked allodynia (Xu et al., 1999) an effect not seen in animals with a clear neuropathic phenotype. There is also evidence of a deficit in the activity of the descending NAergic system in neuropathic pain models (Viisanen and Pertovaara, 2007; Rahman et al., 2008). These results suggest that the level of ongoing tonic activity in the NAergic system may be insufficient to suppress established neuropathic allodynia but may be able to play a role in ameliorating the expression of less severe neuropathic pain phenotypes. Such a functional deficit could explain the efficacy of NAergic re-uptake inhibition in the treatment of neuropathic pain and could explain the lack of effect seen using our AVV-mediated inhibitory strategy.

Viral vectors are being developed for the treatment of neurological conditions including chronic pain (Glorioso and Fink, 2004). A variety of approaches have been explored for pain treatment, including vectors targeted at primary afferent (Wilson et al., 1999; Xu et al., 2003) or spinal dorsal horn (Eaton et al., 2002) neurons, leading to the approval of phase I studies of Herpes simplex-based vectors for cancer pain (Mata et al., 2008). Thus far, no pain studies have targeted descending control systems, hence our vector strategy is novel and we demonstrate that genetic alteration of the excitability of $\sim 150$ pontospinal NAergic neurons can produce a pronociceptive phenotype. Several other genetic approaches have been used to alter the excitability of central catecholaminergic neurons (Salbaum et al., 2004; Han et al., 2006; Hnasko et al., 2006). Pertinently, one of these studies also used retrograde viral transduction to rescue movementdisordered animals lacking dopamine (Hnasko et al., 2006) and others used interventions to increase the excitability of LC neurons [constitutively active CREB (Han et al., 2006) and chlorotoxin (Salbaum et al., 2004)]. This raises the prospect that targeted retrograde genetic upregulation of the pontospinal NAergic system could be used to produce a therapeutic analgesic action.

\section{References}

Akli S, Caillaud C, Vigne E, Stratford-Perricaudet LD, Poenaru L, Perricaudet M, Kahn A, Peschanski MR (1993) Transfer of a foreign gene into the brain using adenovirus vectors. Nat Genet 3:224-228.

Amendola M, Venneri MA, Biffi A, Vigna E, Naldini L (2005) Coordinate dual-gene transgenesis by lentiviral vectors carrying synthetic bidirectional promoters. Nat Biotechnol 23:108-116.

Bewig B, Schmidt WE (2000) Accelerated titering of adenoviruses. Biotechniques 28:870-873.

Bodnar RJ, Mann PE, Stone EA (1985) Potentiation of cold-water swim analgesia by acute, but not chronic desipramine administration. Pharmacol Biochem Behav 23:749-752.

Bohn LM, Xu F, Gainetdinov RR, Caron MG (2000) Potentiated opioid analgesia in norepinephrine transporter knock-out mice. J Neurosci 20:9040-9045.

Burnett A, Gebhart GF (1991) Characterization of descending modulation of nociception from the A5 cell group. Brain Res 546:271-281.

Chaplan SR, Bach FW, Pogrel JW, Chung JM, Yaksh TL (1994) Quantitative assessment of tactile allodynia in the rat paw. J Neurosci Methods 53:55-63.

Clark FM, Proudfit HK (1991a) The projection of noradrenergic neurons in the A7 catecholamine cell group to the spinal cord in the rat demonstrated by anterograde tracing combined with immunocytochemistry. Brain Res 547:279-288

Clark FM, Proudfit HK (1991b) The projection of locus coeruleus neurons to the spinal cord in the rat determined by anterograde tracing combined with immunocytochemistry. Brain Res 538:231-245.

Crawley JN, Roth RH, Maas JW (1979) Locus coeruleus stimulation increases noradrenergic metabolite levels in rat spinal cord. Brain Res 166:180-184

Decosterd I, Woolf CJ (2000) Spared nerve injury: an animal model of persistent peripheral neuropathic pain. Pain 87:149-158.

Dixon WJ (1980) Efficient analysis of experimental observations. Annu Rev Pharmacol Toxicol 20:441-462.

Dodt HU, Zieglgänsberger W (1990) Visualizing unstained neurons in living brain slices by infrared DIC- videomicroscopy. Brain Res 537:333-336.

Duale H, Kasparov S, Paton JF, Teschemacher AG (2005) Differences in transductional tropism of adenoviral and lentiviral vectors in the rat brainstem. Exp Physiol 90:71-78.

Duale H, Waki H, Howorth P, Kasparov S, Teschemacher AG, Paton JF (2007) Restraining influence of A2 neurons in chronic control of arterial pressure in spontaneously hypertensive rats. Cardiovasc Res 76:184-193. 
Dubuisson D, Dennis SG (1977) The formalin test: a quantitative study of the analgesic effects of morphine, meperidine, and brain stem stimulation in rats and cats. Pain 4:161-174.

Eaton MJ, Blits B, Ruitenberg MJ, Verhaagen J, Oudega M (2002) Amelioration of chronic neuropathic pain after partial nerve injury by adenoassociated viral (AAV) vector-mediated over-expression of BDNF in the rat spinal cord. Gene Ther 9:1387-1395.

Eisenach JC, DuPen S, Dubois M, Miguel R, Allin D (1995) Epidural clonidine analgesia for intractable cancer pain. The Epidural Clonidine Study Group. Pain 61:391-399.

Fasmer OB, Berge OG, Tveiten L, Hole K (1986) Changes in nociception after 6-hydroxydopamine lesions of descending catecholaminergic pathways in mice. Pharmacol Biochem Behav 24:1441-1444.

Fields H (2004) State-dependent opioid control of pain. Nat Rev Neurosci 5:565-575.

Fritschy JM, Grzanna R (1990) Demonstration of two separate descending noradrenergic pathways to the rat spinal cord: evidence for an intragriseal trajectory of locus coeruleus axons in the superficial layers of the dorsal horn. J Comp Neurol 291:553-582.

Glorioso JC, Fink DJ (2004) Herpes vector-mediated gene transfer in treatment of diseases of the nervous system. Annu Rev Microbiol 58:253-271.

Graham FL, Prevec L (1995) Methods for construction of adenovirus vectors. Mol Biotechnol 3:207-220.

Green GM, Lyons L, Dickenson AH (1998) Alpha2-adrenoceptor antagonists enhance responses of dorsal horn neurones to formalin induced inflammation. Eur J Pharmacol 347:201-204.

Guyenet PG (1980) The coeruleospinal noradrenergic neurons: anatomical and electrophysiological studies in the rat. Brain Res 189:121-133.

Hammond DL, Yaksh TL (1984) Antagonism of stimulation-produced antinociception by intrathecal administration of methysergide or phentolamine. Brain Res 298:329-337.

Han MH, Bolaños CA, Green TA, Olson VG, Neve RL, Liu RJ, Aghajanian GK, Nestler EJ (2006) Role of cAMP response element-binding protein in the rat locus ceruleus: regulation of neuronal activity and opiate withdrawal behaviors. J Neurosci 26:4624-4629.

Hargreaves K, Dubner R, Brown F, Flores C, Joris J (1988) A new and sensitive method for measuring thermal nociception in cutaneous hyperalgesia. Pain 32:77-88.

Hayashida K, Clayton BA, Johnson JE, Eisenach JC (2008) Brain derived nerve growth factor induces spinal noradrenergic fiber sprouting and enhances clonidine analgesia following nerve injury in rats. Pain 136:348-355.

Hentall ID, Mesigil R, Pinzon A, Noga BR (2003) Temporal and spatial profiles of pontine-evoked monoamine release in the rat's spinal cord. J Neurophysiol 89:2943-2951.

Hnasko TS, Perez FA, Scouras AD, Stoll EA, Gale SD, Luquet S, Phillips PE, Kremer EJ, Palmiter RD (2006) Cre recombinase-mediated restoration of nigrostriatal dopamine in dopamine-deficient mice reverses hypophagia and bradykinesia. Proc Natl Acad Sci U S A 103:8858-8863.

Holden JE, Schwartz EJ, Proudfit HK (1999) Microinjection of morphine in the A7 catecholamine cell group produces opposing effects on nociception that are mediated by alpha1- and alpha2-adrenoceptors. Neuroscience 91:979-990.

Howe MW, Feig SL, Osting SM, Haberly LB (2008) Cellular and subcellular localization of Kir2.1 subunits in neurons and glia in piriform cortex with implications for K+ spatial buffering. J Comp Neurol 506:877-893.

Howorth PW, Teschemacher AG, Pickering AE (2009) Retrograde adenoviral vector targeting of nociresponsive pontospinal noradrenergic neurons in the rat in vivo. J Comp Neurol 512:141-157.

Hwang DY, Carlezon WA Jr, Isacson O, Kim KS (2001) A high-efficiency synthetic promoter that drives transgene expression selectively in noradrenergic neurons. Hum Gene Ther 12:1731-1740.

Iadarola MJ, Brady LS, Draisci G, Dubner R (1988) Enhancement of dynorphin gene expression in spinal cord following experimental inflammation: stimulus specificity, behavioral parameters and opioid receptor binding. Pain 35:313-326.

Jasmin L, Tien D, Weinshenker D, Palmiter RD, Green PG, Janni G, Ohara PT (2002) The NK1 receptor mediates both the hyperalgesia and the resistance to morphine in mice lacking noradrenaline. Proc Natl Acad Sci U S A 99:1029-1034.

Jasmin L, Boudah A, Ohara PT (2003) Long-term effects of decreased nor- adrenergic central nervous system innervation on pain behavior and opioid antinociception. J Comp Neurol 460:38-55.

Johns DC, Marx R, Mains RE, O’Rourke B, Marbán E (1999) Inducible genetic suppression of neuronal excitability. J Neurosci 19:1691-1697.

Jones SL (1991) Descending noradrenergic influences on pain. Prog Brain Res 88:381-394.

Jones SL, Gebhart GF (1986a) Characterization of coeruleospinal inhibition of the nociceptive tail-flick reflex in the rat: mediation by spinal alpha 2-adrenoceptors. Brain Res 364:315-330.

Jones SL, Gebhart GF (1986b) Quantitative characterization of ceruleospinal inhibition of nociceptive transmission in the rat. J Neurophysiol 56:1397-1410.

Karschin C, Dissmann E, Stühmer W, Karschin A (1996) IRK(1-3) and GIRK(1-4) inwardly rectifying $\mathrm{K}^{+}$channel mRNAs are differentially expressed in the adult rat brain. J Neurosci 16:3559-3570.

Kubo Y, Baldwin TJ, Jan YN, Jan LY (1993) Primary structure and functional expression of a mouse inward rectifier potassium channel. Nature 362:127-133.

Li X, Conklin D, Ma W, Zhu X, Eisenach JC (2002) Spinal noradrenergic activation mediates allodynia reduction from an allosteric adenosine modulator in a rat model of neuropathic pain. Pain 97:117-125.

Liu RJ, Wang R, Nie H, Zhang RX, Qiao JT, Dafny N (1997a) Effects of intrathecal monoamine antagonists on the nociceptive c-Fos expression in a lesioned rat spinal cord. Int J Neurosci 91:169-180.

Liu Y, Himes BT, Moul J, Huang W, Chow SY, Tessler A, Fischer I (1997b) Application of recombinant adenovirus for in vivo gene delivery to spinal cord. Brain Res 768:19-29.

Lonergan T, Teschemacher AG, Hwang DY, Kim KS, Pickering AE, Kasparov S (2005) Targeting brain stem centers of cardiovascular control using adenoviral vectors: impact of promoters on transgene expression. Physiol Genomics 20:165-172.

Loughlin SE, Foote SL, Bloom FE (1986) Efferent projections of nucleus locus coeruleus: topographic organization of cells of origin demonstrated by three-dimensional reconstruction. Neuroscience 18:291-306.

Ma W, Eisenach JC (2003) Chronic constriction injury of sciatic nerve induces the up-regulation of descending inhibitory noradrenergic innervation to the lumbar dorsal horn of mice. Brain Res 970:110-118.

Mansikka H, Lähdesmäki J, Scheinin M, Pertovaara A (2004) Alpha(2A) adrenoceptors contribute to feedback inhibition of capsaicin-induced hyperalgesia. Anesthesiology 101:185-190.

Martin WJ, Gupta NK, Loo CM, Rohde DS, Basbaum AI (1999) Differential effects of neurotoxic destruction of descending noradrenergic pathways on acute and persistent nociceptive processing. Pain 80:57-65.

Mata M, Hao S, Fink DJ (2008) Applications of gene therapy to the treatment of chronic pain. Curr Gene Ther 8:42-48.

Melzack R, Wall PD, Ty TC (1982) Acute pain in an emergency clinic: latency of onset and descriptor patterns related to different injuries. Pain 14:33-43.

Millan MJ (1997) The role of descending noradrenergic and serotoninergic pathways in the modulation of nociception: focus on receptor multiplicity. In: The pharmacology of pain (Dickenson A, Besson JM, eds), pp 385-446. Berlin: Springer.

Millan MJ (2002) Descending control of pain. Prog Neurobiol 66:355-474. Miller JF, Proudfit HK (1990) Antagonism of stimulation-produced antinociception from ventrolateral pontine sites by intrathecal administration of alpha-adrenergic antagonists and naloxone. Brain Res 530:20-34.

Mizuno H, Hirano T, Tagawa Y (2007) Evidence for activity-dependent cortical wiring: formation of interhemispheric connections in neonatal mouse visual cortex requires projection neuron activity. J Neurosci 27:6760-6770.

North RA, Yoshimura M (1984) The actions of noradrenaline on neurones of the rat substantia gelatinosa in vitro. J Physiol 349:43-55.

Omote K, Kawamata T, Kawamata M, Namiki A (1998) Formalin-induced nociception activates a monoaminergic descending inhibitory system. Brain Res 814:194-198.

Paxinos G, Watson C (2005) The rat brain in stereotaxic coordinates, Ed 5. Amsterdam: Elsevier Academic.

Pertovaara A (2006) Noradrenergic pain modulation. Prog Neurobiol 80:53-83.

Rahman W, D'Mello R, Dickenson AH (2008) Peripheral nerve injuryinduced changes in spinal alpha(2)-adrenoceptor-mediated modulation 
of mechanically evoked dorsal horn neuronal responses. J Pain 9:350-359.

Reddy SV, Maderdrut JL, Yaksh TL (1980) Spinal cord pharmacology of adrenergic agonist-mediated antinociception. J Pharmacol Exp Ther 213:525-533.

Reynolds DV (1969) Surgery in the rat during electrical analgesia induced by focal brain stimulation. Science 164:444-445.

Ridoux V, Robert JJ, Zhang X, Perricaudet M, Mallet J, Le Gal La Salle G (1994) Adenoviral vectors as functional retrograde neuronal tracers. Brain Res 648:171-175.

Sagen J, Proudfit HK (1984) Effect of intrathecally administered noradrenergic antagonists on nociception in the rat. Brain Res 310:295-301.

Salbaum JM, Cirelli C, Walcott E, Krushel LA, Edelman GM, Tononi G (2004) Chlorotoxin-mediated disinhibition of noradrenergic locus coeruleus neurons using a conditional transgenic approach. Brain Res 1016:20-32.

Sluka KA, Westlund KN (1992) Spinal projections of the locus coeruleus and the nucleus subcoeruleus in the Harlan and the Sasco SpragueDawley rat. Brain Res 579:67-73.

Sonohata M, Furue H, Katafuchi T, Yasaka T, Doi A, Kumamoto E, Yoshimura M (2004) Actions of noradrenaline on substantia gelatinosa neurones in the rat spinal cord revealed by in vivo patch recording. J Physiol 555:515-526.

Stone LS, MacMillan LB, Kitto KF, Limbird LE, Wilcox GL (1997) The $\alpha_{2 \mathrm{a}}$ adrenergic receptor subtype mediates spinal analgesia evoked by $\alpha_{2}$ agonists and is necessary for spinal adrenergic-opioid synergy. J Neurosci 17:7157-7165.

Stoppini L, Buchs PA, Muller D (1991) A simple method for organotypic cultures of nervous tissue. J Neurosci Methods 37:173-182.

Sugimoto M, Kuraishi Y, Satoh M, Takagi H (1986) Involvement of medullary opioid-peptidergic and spinal noradrenergic systems in the regulation of formalin-induced persistent pain. Neuropharmacology 25:481-485.

Teschemacher AG, Paton JF, Kasparov S (2005) Imaging living central neurones using viral gene transfer. Adv Drug Deliv Rev 57:79-93.

Tsuruoka M, Willis WD Jr (1996) Bilateral lesions in the area of the nucleus locus coeruleus affect the development of hyperalgesia during carrageenaninduced inflammation. Brain Res 726:233-236.

Viisanen H, Pertovaara A (2007) Influence of peripheral nerve injury on response properties of locus coeruleus neurons and coeruleospinal antinociception in the rat. Neuroscience 146:1785-1794.

Wang S, Teschemacher AG, Paton JF, Kasparov S (2006) Mechanism of nitric oxide action on inhibitory GABAergic signaling within the nucleus tractus solitarii. FASEB J 20:1537-1539.

Wei F, Dubner R, Ren K (1999) Nucleus reticularis gigantocellularis and nucleus raphe magnus in the brain stem exert opposite effects on behavioral hyperalgesia and spinal Fos protein expression after peripheral inflammation. Pain 80:127-141.

Wei H, Pertovaara A (2006) Spinal and pontine alpha2-adrenoceptors have opposite effects on pain-related behavior in the neuropathic rat. Eur J Pharmacol 551:41-49.

West WL, Yeomans DC, Proudfit HK (1993) The function of noradrenergic neurons in mediating antinociception induced by electrical stimulation of the locus coeruleus in two different sources of Sprague-Dawley rats. Brain Res 626:127-135.

Westlund KN, Bowker RM, Ziegler MG, Coulter JD (1983) Noradrenergic projections to the spinal cord of the rat. Brain Res 263:15-31.

Williams JT, Marshall KC (1987) Membrane properties and adrenergic responses in locus coeruleus neurons of young rats. J Neurosci 7:3687-3694.

Williams JT, North RA, Shefner SA, Nishi S, Egan TM (1984) Membrane properties of rat locus coeruleus neurones. Neuroscience 13:137-156.

Wilson SP, Yeomans DC, Bender MA, Lu Y, Goins WF, Glorioso JC (1999) Antihyperalgesic effects of infection with a preproenkephalin-encoding herpes virus. Proc Natl Acad Sci U S A 96:3211-3216.

Xu M, Kontinen VK, Kalso E (1999) Endogenous noradrenergic tone controls symptoms of allodynia in the spinal nerve ligation model of neuropathic pain. Eur J Pharmacol 366:41-45.

Xu Y, Gu Y, Xu GY, Wu P, Li GW, Huang LY (2003) Adeno-associated viral transfer of opioid receptor gene to primary sensory neurons: a strategy to increase opioid antinociception. Proc Natl Acad Sci U S A 100: 6204-6209.

Yeomans DC, Clark FM, Paice JA, Proudfit HK (1992) Antinociception induced by electrical stimulation of spinally projecting noradrenergic neurons in the A7 catecholamine cell group of the rat. Pain 48:449-461.

Yu CR, Power J, Barnea G, O’Donnell S, Brown HE, Osborne J, Axel R, Gogos JA (2004) Spontaneous neural activity is required for the establishment and maintenance of the olfactory sensory map. Neuron 42:553-566. 